\title{
$\mathrm{HEVC}$ 의 계층적 부호화 구조를 고려한 LCU 단위의 비트율 제어 기법
}

\author{
박 동 일a), 김 재 곤 ${ }^{\ddagger}{ }^{\ddagger}$, 임 성 창b), 김 종 호 ${ }^{b)}$, 김 휘 용 ${ }^{b)}$
}

\section{LCU-Level Rate Control for HEVC Considering Hierarchical Coding Structure}

\author{
Dong-Il Park ${ }^{\text {a)}}$, Jae-Gon Kim ${ }^{\text {a) }}$, Sung-Chang Lim $^{\text {b) }}$, Jongho Kim ${ }^{\text {b) }}$, and Hui-Yong Kim ${ }^{\text {b) }}$ \\ 요 약
}

본 논문에서는 현재 표준화가 진행중인 HEVC(High Efficiency Video Coding)의 고정 비트율(CBR: Constant Bitrate) 부호화를 위 한 비트율 제어(rate control) 기법을 다룬다. 기존의 H.264/AVC의 비트율 제어 기법에서는 계층적 부호화 구조의 특성을 고려하지 못 한 제어 기법을 사용하여 정확한 비트율 제어에 어려움이 있다. 현재 HEVC의 참조 소프트웨어인 $\mathrm{HM}(\mathrm{HEVC}$ test Model)에는 $\mathrm{CBR}$ 부호화를 위한 비트율 제어 알고리즘이 제공되지 않은 상태이며, 추후 비트율 제어 모듈이 추가될 것으로 예상된다. 이때 $\mathrm{HM}$ 의 공통 실험조건에 정의된 임의접근(Random Access: RA) 모드의 계층적 부호화 구조에서의 보다 정확한 비트율 제어가 요구된다. 따라서, 본 논문에서는 계층적 부호화 구조에서의 효율적인 비트율 제어를 위해 2차 비트율-왜곡(Rate-Distortion: R-D) 모델 기반의 시간계층 및 프레임 타입에 따른 비트율 특성을 반영한 비트율 제어 기법을 제시한다. 또한, 제어 단위에 따른 비트 변동율과 화질 손실 간에 발생하는 상충관계를 고려하여 비트율 제어 단위를 프레임 단위와 $\mathrm{HEVC}$ 의 기본 부호화 단위(Coding Unit: $\mathrm{CU}$ )로 설정하고 모의실 험을 통해 계층적 부호화 구조를 위해 제시된 기법의 비트율 제어 성능을 확인한다.

\section{Abstract}

In this paper, a method of rate control for constant bitrate (CBR) coding of High Efficiency Video Coding (HEVC) is addressed. The existing rate control of H.264/AVC may not provide exact rate control in the case of hierarchical coding structure since it doesn't consider the characteristics of the hierarchical coding structure. It is expected that a rate control is added to the reference software called HM for CBR encoding in the near future. More accurate rate control may be required in a hierarchical structure of random access (RA) mode defined in the common test condition of HM. In this paper, we propose a method of rate control based on quadratic Rate-Distortion (R-D) model considering temporal layers and frame types in hierarchical coding structure for efficient rate control. In the consideration of the trade-off relationship between the bit fluctuation and the average PSNR, both of frame and coding unit $(\mathrm{CU})$ are set as the basic unit of rate control. The performance of the proposed rate control method is verified by simulations along with the trade-off relationships for the both cases of basic unit.

Keywords: Rate Control, HEVC, Hierarchical Coding Structure, LCU

a) 한국항공대학교 항공전자 및 정보통신공학부

School of Electronics, Telecommunication \& Computer Engineering, Korea Aerospace University

b) 한국전자통신연구원 방통융합미디어연구부 실감미디어연구팀

Realistic Media Research Team, ETRI

‡ 교신저자 : 김재곤(jgkim@kau.ac.kr)

※본 연구는 방송통신위원회의 ETRI 연구지원 사업[KCA-2011-(11921-02001), 무안경 다시점 3D 지원 UHDTV 방송 기술개발] 및 지식경제부 및 정보 통신산업진훙원의 대학 IT 연구센터 지원사업[NIPA-2011-(C1090-1111-0001)]의 지원으로 수행되었음.

· 접수일(2011년7월18일), 수정일(2011년8월22일),게재확정일(2011년8월22일) 


\section{I. 서 론}

$\mathrm{ISO} / \mathrm{IEC} \mathrm{MPEG}$ 과 ITU-T VCEG의 공동 작업반인 JCT-VC(Joint Collaboration Team on Video Coding)에서 는 초고해상도(UHD: Ultra HD) 비디오 부호화를 주 목표 로 한 HEVC(High Efficiency Video Coding) 표준화 ${ }^{[1]}$ 를 진행하고 있다. 지난해 10 월 광저우에서 개최된 3 차 회의에 서는 $\mathrm{HEVC}$ 의 참조 소프트웨어인 $\mathrm{HM}(\mathrm{HEVC}$ test Model) 1.0 에 포함될 기술 ${ }^{[2]}$ 이 결정되었고, 올해 3 월 제네바 5 차 회의에 걸쳐 $\mathrm{HM} 3.0^{[3]}$ 에 포함될 기술이 채택되었다. $\mathrm{HEVC}$ 의 표준화 단계에서는 공통 실험조건 ${ }^{[4]}$ 을 명시하고 $\mathrm{HM}$ 의 부호화 모드로 Intra-only, 저지연(Low-Delay: LD), 그리고 임의접근(Random Access: RA)의 3가지 모드를 정 의하고 있다. 한편, $\mathrm{HM}$ 에서는 아직 고정 비트율(CBR: Constant Bitrate) 부호화를 위한 비트율 제어를 제공하고 있지 않으며, 추후 비트율 제어 모듈이 추가될 것으로 예상 된다.

본 논문에서는 $\mathrm{HEVC}$ 의 공통 실험조건에서 명시하는 $\mathrm{RA}$ 부호화 모드에서의 비트율 제어 기법을 제안한다. RA 모드는 방송 및 저장 응용 등에서 사용될 수 있도록 주기적 으로 I-프레임을 삽입하는 것을 특징으로 하며, LD 모드와 달리 역방향 예측이 허용되는 특징을 갖는다. 따라서 RA 모드에서는 양방향 예측을 포함한 계층적-B(HierarchicalB) 구조를 사용할 수 있으며, 이를 통해 시간적 스케일러빌 리티를 지원할 수 있을 뿐만 아니라 더 높은 부호화 효율을 얻을 수 있다.

기존 H.264/AVC ${ }^{[5]}$ 의 JM(Joint Model) ${ }^{[6]}$ 에는 계층적 부 호화 모드를 포함한 비트율 제어 기법 ${ }^{[7][8]}$ 이 제안 및 구현되 어 있다. [7]은 IPPP 구조와 비참조 프레임을 사용하는 구 조에 적합하도록 제안되어 계층적 부호화 구조를 고려하지 않고 버퍼 레벨과 프레임 복잡도 만을 고려하여 비트할당 을 하고 있다. [8]에서는 계층적-B 구조를 고려한 기법을 제시하였지만, $\mathrm{P}$-프레임들의 부호화 결과와 현재 시간계층 을 이용하여 I-와 B-프레임의 양자화 파라미터(Quantization Parameter: $\mathrm{QP}$ )를 결정하는 방식을 사용하므로 초기 $\mathrm{QP}$ 에 따라 영향을 많이 받으며 정확한 비트율 제어가 어렵 다. [9]는 H.264/SVC의 스케일러블 부호화 구조를 고려한
것으로 시간계층 별 비트할당 방식을 제시하였고, [10]은 계층적 부호화 구조를 고려한 개선된 비트율-양자화 모델 을 제시하고 시간계층 및 프레임 타입을 반영하여 비트율 제어의 정확성을 높였다.

본 논문에서는 $\mathrm{HEVC}$ 의 계층적-B 구조에서의 효율적인 비트율 제어를 위해 모든 시간계층과 프레임 타입에 대해 2차 R-D 모델을 적용함으로써 각 시간계층과 프레임 타입 의 특성이 반영된 $\mathrm{QP}$ 를 결정하는 비트율-제어 기법을 제시 하고 그 결과를 확인한다.

또한, JM에서는 비트율 제어를 수행하는 기본적인 단위 로 기본단위(Basic Unit: BU)를 정의하고 있으며, 이 기본 단위는 한 프레임으로부터 매크로블록(MB)까지 설정이 가 능하다. 이 기본단위는 율제어의 비트율 변동과 PSNR 화 질간의 상충관계를 고려하여 프레임, $\mathrm{MB}$ 또는 그 사이의

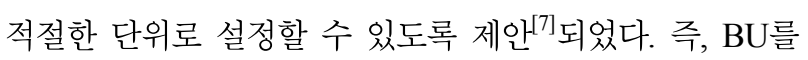
하나의 프레임으로 설정할 경우, 높은 PSNR과 프레임 간 높은 비트율 변동을 보이는 반면, $\mathrm{MB}$ 단위의 제어는 낮은 비트율 변동과 약간의 PSNR 손실을 갖는다. 따라서, 효율 적인 비트율 제어를 위해서는 적절한 $\mathrm{BU}$ 의 설정이 요구된 다.

현재 HEVC에서는 초고해상도(Ultra HD: UHD) 비디오 의 효율적인 부호화를 위해 기존의 $16 \times 16$ 크기의 $\mathrm{MB}$ 를 확 장한 다양한 블록 크기를 갖는 $\mathrm{CU}\left(\right.$ Coding Unit) 구조 ${ }^{[1]}$ 를 정의하고 있다. $\mathrm{CU}$ 는 적용 범위에 따라 최대 블록 크기와 최대 깊이 정보를 이용하여 $16 \times 16$ 이상의 블록 크기도 지 원 가능하지만 복잡도와 성능에 따라 현재 최대 크기로 LCU(Largest Coding Unit)를 64x64 크기로 설정하여 표준 화가 진행 중이다. 따라서, 본 논문에서는 비트율 제어를 위한 $\mathrm{BU}$ 를 프레임 및 $\mathrm{LCU}$ 로 제안 및 구현하여 그 결과를 확인하고자 한다.

본 논문의 구성은 다음과 같다. 제 2 장에서는 기존 H.264/ AVC의 비트율 제어 기법에 대해 기술하고, 제 3 장에서는 $\mathrm{HEVC}$ 의 계층적-B 부호화 구조를 위해 제안한 비트할당 및 $\mathrm{QP}$ 결정 기법을 기술하고, 제 4 장에서는 제안 한 비트율 제어 실험결과를 보이고, 마지막으로 제 5 장에 서 결론을 맺는다. 


\section{H.264/AVC 비트율 제어 기법}

본 장에서는 H.264/AVC의 참조 소프트웨어인 JM에 구 현되어 있는 비트율 제어 방식에 대해 기술한다. JM은 가 변 비트율(VBR: Variable Bitrate)과 고정 비트율(CBR: Constant Bitrate) 방식을 모두 지원하지만, 본 논문에서는 $\mathrm{CBR}$ 방식에 대해서만 논한다.

\section{1. 프레임 목표 비트량 할당}

H.264/AVC의 비트율 제어는 크게 GOP(Group of Picture), 프레임, 기본단위 레벨 순으로 진행된다. 기본적으로, $\mathrm{GOP}$ 에 할당되는 비트량은 GOP 내에 포함되는 모든 프레 임들에 대한 할당량이며, 한 프레임이 부호화된 이후마다 갱신된다. 이 때 $\mathrm{GOP}$ 에 할당된 남은 비트량에 대해 복잡도 와 버퍼 레벨을 고려하여 $\mathrm{P}$-프레임에 대한 비트할당을 한 다. 이 때, 가상버퍼 점유량 $\left(B_{c}\left(n_{i, j+1}\right)\right)$ 과 목표 버퍼레벨 $\left(\operatorname{Tbl}\left(n_{i, j+1}\right)\right)$ 은 다음 식 (1)와 (2)과 같이 유동적으로 변하 는 유동 트래픽 모델(Fluid flow traffic model) ${ }^{[7]}$ 을 따른다.

$$
\begin{aligned}
& B_{c}\left(n_{i, j+1}\right)=B_{c}\left(n_{i, j}\right)+b\left(n_{i, j}\right)-\frac{u\left(n_{i, j}\right)}{F_{r}} \\
& \operatorname{Tbl}\left(n_{i, j+1}\right)= \operatorname{Tbl}\left(n_{i, j}\right)-\frac{\operatorname{Tbl}\left(n_{i, 2}\right)}{N_{p}-1}+ \\
& \frac{\widetilde{W}_{p}\left(n_{i, j}\right) \times\left(N_{B}+1\right) \times u\left(n_{i, j}\right)}{F_{r} \times\left(\widetilde{W}_{p}\left(n_{i, j}\right)+\widetilde{W}_{b}\left(n_{i, j}\right) \times N_{B}\right.}-\frac{u\left(n_{i, j}\right)}{F_{r}}
\end{aligned}
$$

식 (1)에서 $b\left(n_{i, j}\right)$ 는 $i$ 번째 GOP 내의 $j$ 번째 프레임에 대해 부호화된 비트량이고, $u\left(n_{i, j}\right)$ 는 채널 대역폭이고, $F_{r}$ 은 초당 부호화된 프레임 율을 나타낸다. 식 (2)의 $N_{p}$ 는 $\mathrm{GOP}$ 내에 있는 P-프레임의 개수를 의미하고, $N_{B}$ 는 GOP 내의 B-프레임의 수를 의미하며 $\widetilde{W}_{p}\left(n_{i, j}\right)$ 와 $\widetilde{W}_{b}\left(n_{i, j}\right)$ 는 P프레임과 B-프레임의 평균 복잡도 비중을 의미한다. 현재 부호화하고자 하는 프레임의 목표 비트량을 예측하기 위해 가상버퍼 점유량 $\operatorname{Tbl}\left(n_{i, j}\right)$ 및 목표 버퍼레벨 $B_{c}\left(n_{i, j}\right)$ 을 이 용하여 다음 식 (3)과 같이 버퍼량 $\widetilde{T}\left(n_{i, j}\right)$ 을 예측한다.

$$
\widetilde{T}\left(n_{i, j}\right)=\frac{u\left(n_{i, j}\right)}{F_{r}}+\gamma \times\left(\operatorname{Tbl}\left(n_{i, j}\right)-B_{c}\left(n_{i, j}\right)\right)
$$

이와 같이, 현재 프레임의 버퍼량이 예측되면 다음 식 (4) 에서 예측한 부호화 비트량 $\hat{T}\left(n_{i, j}\right)$ 과 함께 고려하여 식 (5) 과 같이 최종적으로 목표 비트량 $T\left(n_{i, j}\right)$ 을 결정한다.

$$
\begin{gathered}
=\frac{\hat{T}\left(n_{i, j}\right)}{W_{p}\left(n_{i, j-1}\right) \times N_{p, r}(j-1)+W_{b}\left(n_{i, j-1}\right) \times N_{b, r}(j-1)} \\
T\left(n_{i, j}\right)=\beta \times \hat{T}\left(n_{i, j}\right)+(1-\beta) \times \tilde{T}\left(n_{i, j}\right)
\end{gathered}
$$

식 (4)는 GOP 내에 존재하는 프레임들의 부호화에 할당 할 수 있는 비트량 $T_{r}\left(n_{i, j}\right)$ 과 현재 GOP 내의 부호화하지 않은 P-프레임과 B-프레임의 수 $N_{p, r}(j-1), N_{b, r}(j-1)$ 와 복잡도 $W_{p}\left(n_{i, j-1}\right), W_{b}\left(n_{i, j-1}\right)$ 를 고려한 전체 복잡도 중에 현재 P-프레임의 복잡도의 비중을 이용하여 계산한다.

\section{2. $\mathrm{MAD}$ 예측 및 $\mathrm{QP}$ 결정}

현재 프레임에 대한 복잡도를 예측하는데 사용되는 $\mathrm{MAD}$ (Mean Absolute Difference)는 R-D 최적화(RDO: Rate Distortion Optimization) 기반의 부호화 구조와 QP를 결정하는 비트율 제어 모듈 간의 chicken-and-egg 딜레마 ${ }^{[7]}$ 로 인해 식 (6)과 같이 선형 예측값을 계산하여 비트율 제어 에 사용한다.

$$
M A D_{c}=a_{1} \times M A D_{p}+a_{2}
$$

이 때의 $M A D_{c}$ 는 예측한 현재 프레임의 왜곡값을, $M A D_{p}$ 는 이전 프레임의 실제 왜곡값을 나타낸다. 현재 프 레임의 복잡도를 반영하는 예측 왜곡값 $M A D_{c}$ 와 목표 비트 량 $T\left(n_{i, j}\right)$ 을 이용하여 식 (7)와 같이 2차 R-D 모델 ${ }^{[7]}$ 에 적 용하여 양자화 단계 $Q_{s t e p}$ 을 계산한다.

$$
\frac{T\left(n_{i, j}\right)}{M A D_{c}}=\frac{x_{1}}{Q_{\text {step }}}+\frac{x_{2}}{Q_{\text {step }}^{2}}
$$


이 때의 $x_{1}, x_{2}$ 는 이미 부호화된 이전 프레임으로부터 얻 는 2차 R-D 모델의 파라미터 값이다.

\section{3. 계층적-B 부호화 구조를 위한 $\mathrm{B}-$ 프레임의 QP 결정}

$\mathrm{JM}$ 의 초기 버전은 비참조 $\mathrm{B}$-프레임을 포함하는 부호화 구조를 고려한 것으로, 계층적-B 부호화 구조를 위한 비트 율 제어 기법은 추가로 제안되었다. 초기 버전에서 고려하 던 비참조 $\mathrm{B}$-프레임을 포함하는 구조가와 달리, [8]에서는 $\mathrm{B}$-프레임이 다른 시간계층의 프레임을 부호화하는데 참조 영상으로 사용되는 계층적-B 부호화 구조를 고려하여 B-프 레임의 $\mathrm{QP}$ 를 결정한다. 식 (8)에 의해 이전 $\mathrm{QP}$ 의 값 $Q P_{p r e v}$ 이 먼저 계산된다.

$$
Q P_{\text {prev }}=\max \left(Q P_{1}, Q P_{2}\right)
$$

이 때의 $Q P_{1}, Q P_{2}$ 는 참조 프레임 리스트인 List 0 와 List 1 예측 방향을 구성하는 I- 혹은 P-프레임이다. 다음 단계 로, 계층적 부호화 구조일 때 계층적 레벨 수 $H_{\text {levels }}$ 이 계산 된다. 예를 들면, 그림 1 과 같이 I- 또는 P-프레임 사이에 3 개의 $\mathrm{B}$-프레임이 있다면 $H_{\text {levels }}=2$ 가 된다. 부호화 구조 와 재생 순서의 쌍이 $\mathrm{I}_{0} \mathrm{~b}_{1} \mathrm{~B}_{2} \mathrm{~b}_{3} \mathrm{P}_{4}(\mathrm{~B}$ 는 참조 프레임으로 사용되고, $\mathrm{b}$ 는 비참조 프레임을 의미함)로 주어질 때, $\mathrm{b}_{1}$ 과 $\mathrm{b}_{3}$ 는 레벨 0 에 속하는 반면, $\mathrm{B}_{2}$ 는 레벨 1 에 속한다. 그러나, 부호화 순서는 $\mathrm{I}_{0} \mathrm{P}_{4} \mathrm{~B}_{2} \mathrm{~b}_{1} \mathrm{~b}_{3}$ 이므로 $\mathrm{B}$-프레임 부호화 순

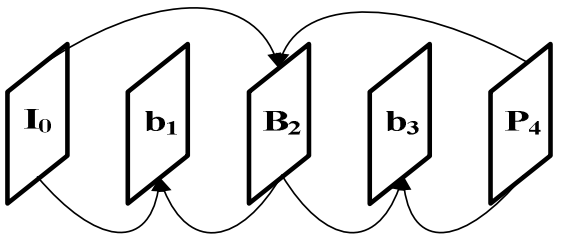

\begin{tabular}{|c|c|c|c|c|c|}
\hline & $\mathrm{I}_{0}$ & $\mathrm{~b}_{1}$ & $\mathrm{~B}_{2}$ & $\mathrm{~b}_{3}$ & $\mathrm{P}_{4}$ \\
\hline $\mathbf{B}_{\text {order }}$ & $\mathrm{x}$ & 1 & 0 & 2 & $\mathrm{x}$ \\
\hline $\mathbf{L}\left(\mathbf{B}_{\text {order }}\right)$ & $\mathrm{x}$ & 0 & 1 & 0 & $\mathrm{x}$ \\
\hline $\mathbf{Q P}$ & 10 & 12 & 11 & 12 & 10 \\
\hline
\end{tabular}

그림 1. JM에서의 계층적 부호화 구조를 위한 $\mathrm{QP}$ 결정

Fig. 1. QP decision for hierarchical coding structure in JM
서 $B_{\text {order }}$ 는 0, 1, 그리고 2가 $\mathrm{B}_{2}, \mathrm{~b}_{1}, \mathrm{~b}_{3}$ 에 해당된다. $L(n)$ 을 $\mathrm{B}$-프레임의 부호화 순서 $n$ 일 때의 계층적 레벨이라고 할 때, 식 (9)과 같이 계층적 부호화 구조의 B-프레임에 대한 $\mathrm{QP}$ 값이 계산된다. 즉, 계층적 부호화 구조를 구려하여, 시 간계층이 높은 레벨에 포함되는 프레임에 대해 높은 $\mathrm{QP}$ 를 할당하여 부호화 효율을 최대화하였다.

$$
\widetilde{Q B}_{B_{\text {order }}}=Q P_{\text {prev }}+H_{\text {levels }}-L\left(B_{\text {order }}\right)
$$

\section{4. 비트율 제어 결과}

[8]에서 제안한 계층적 부호화 구조를 위한 비트율 제어 기법의 성능을 확인한다. $\mathrm{JM}$ 에서는 비트율 제어를 위한 총 4개의 모드를 제공하고 있는데, 비참조 $\mathrm{B}$-프레임 구조를 위 해 제안된 초기 모델인 0 번 모드, 프레임 타입이 모두 같은 경우인 I only, IPPPP, 혹은 IBBBB와 같은 구조를 위한 1 번 모드, 계층적 부호화 구조를 위한 2,3 번 모드를 제공하 고 있다. 앞서 설명한 비트율 제어 방식은 2 번 모드에 해당 된다. 2, 3번 모드를 통한 고정 비트율 제어를 통한 성능을 확인해본다. JM 16.2버전을 이용하였고, 비트율 제어를 위 한 실험 조건은 표 1 과 같다. 표 2의 결과와 같이 목표 비트 율 대비 실제 발생 평균 비트율은 2번 모드의 경우, $5.52 \%$

표 1. 비트율 제어 실험 조건

Table 1. Test conditions for rate control

\begin{tabular}{|c|c|}
\hline 부호화 파라미터 & 설정값 \\
\hline $\begin{array}{c}\text { Resolution } \\
\text { (framerate) }\end{array}$ & $\begin{array}{c}\text { 1920x1080(Kimono, ParkScene(24), } \\
\text { BasketballDrive(50), BQTerrace(60)) } \\
\text { 1920x544(KBS2, MBC2(60)) }\end{array}$ \\
\hline GOP size & 8 \\
\hline Intra period & $\begin{array}{c}24 \text { for } 24 \mathrm{fps} \\
48 \text { for } 50 \mathrm{fps} \\
64 \text { for } 60 \mathrm{fps}\end{array}$ \\
\hline Length & 10 초 \\
\hline Reference frames & 4 \\
\hline Search mode & EPZS \\
\hline Search range & 64 \\
\hline Symbol mode & CABAC \\
\hline Bit depth & 8 \\
\hline
\end{tabular}


표 2. JM을 이용한 비트율 제어 결과

Table 2. Experimental results of rate control using JM

\begin{tabular}{|c|c|c|c|c|c|c|c|}
\hline \multirow{2}{*}{$\begin{array}{c}\text { Sequence } \\
\text { (Framerate) }\end{array}$} & \multirow{2}{*}{$\begin{array}{c}\text { Target } \\
\text { Bitrate[kbps] }\end{array}$} & $\begin{array}{c}\text { Actual } \\
\text { Bitrate[kbps] }\end{array}$ & $\begin{array}{c}\text { PSNR } \\
{[\mathrm{Y} \text {-dB] }}\end{array}$ & $\begin{array}{c}\text { Error } \\
{[\%]}\end{array}$ & $\begin{array}{c}\text { Actual } \\
\text { Bitrate[kbps] }\end{array}$ & $\begin{array}{c}\text { PSNR } \\
{[\mathrm{Y} \text {-dB] }]}\end{array}$ & $\begin{array}{c}\text { Error } \\
{[\%]}\end{array}$ \\
\cline { 3 - 8 } & 1800 & 1795.58 & 36.98 & 0.25 & 2225.63 & 34.65 & 23.65 \\
\hline \hline Kimono (24) & 5050 & 5137.51 & 37.30 & 1.73 & 5003.45 & 36.18 & 0.92 \\
\hline ParkScene (24) & 5940 & 6358.08 & 36.03 & 7.04 & 5909.31 & 33.80 & 0.52 \\
\hline BasketballDrive (50) & 6000 & 6724.62 & 34.25 & 12.08 & 5952.47 & 33.62 & 0.79 \\
\hline BQTerrace (60) & 11000 & 11827.10 & 36.90 & 7.52 & 11506.21 & 36.53 & 4.60 \\
\hline KBS2 (60) & 6000 & 6269.12 & 41.33 & 4.49 & 6524.05 & 38.89 & 8.73 \\
\hline MBC2 (60) & & & 5.52 & & & 6.54 \\
\hline \hline Average & & & & & & & \\
\hline
\end{tabular}

의 오차율을 보이고, 3 번 모드의 경우, $6.54 \%$ 의 오차율이 발생함을 확인하였다. 추가적으로, 고정 비트율의 성능을 확인하기 위해, 그림 2 와 같이, 초당 발생 비트량을 도식화

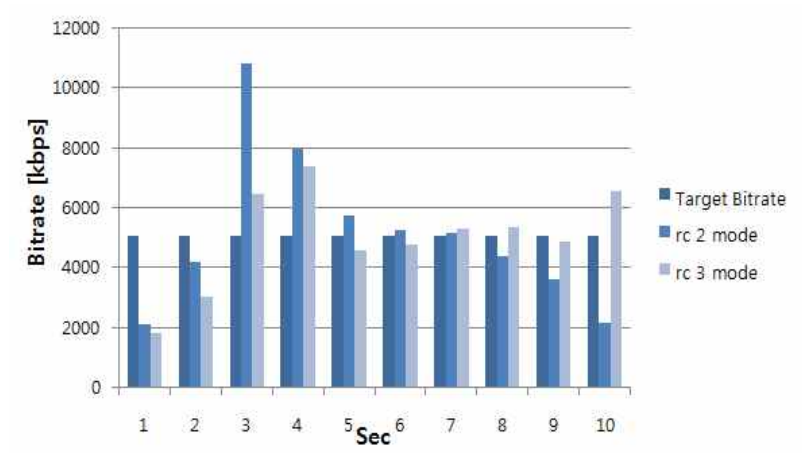

(a) ParkScene, $24 \mathrm{fps}$

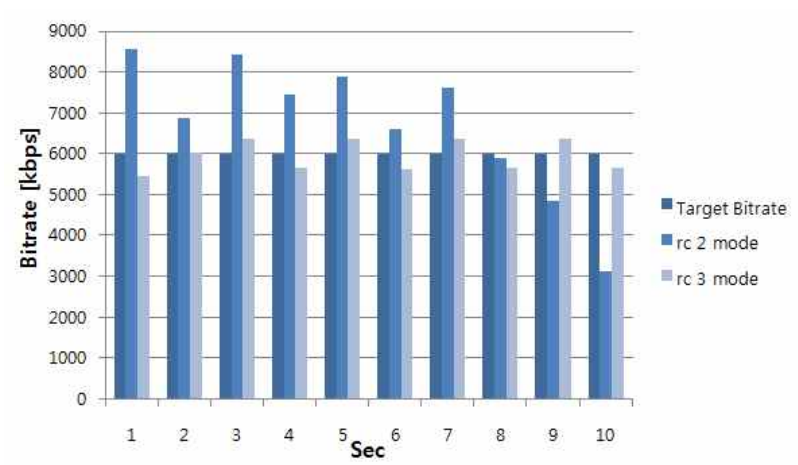

(c) BQTerrace, $60 \mathrm{fps}$
하였다. 설정한 초당 비트율 대비 실제 발생 비트량은 비트 율 변동이 큰 것을 확인할 수 있다. 이는 JM에서 계층적 부호화 구조에 따른 GOP 단위의 효율적인 비트율 제어가

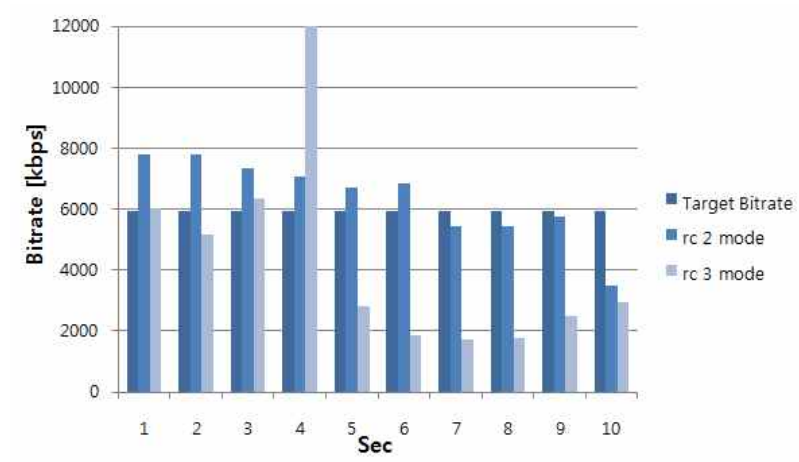

(b) BasketballDrive, $50 \mathrm{fps}$

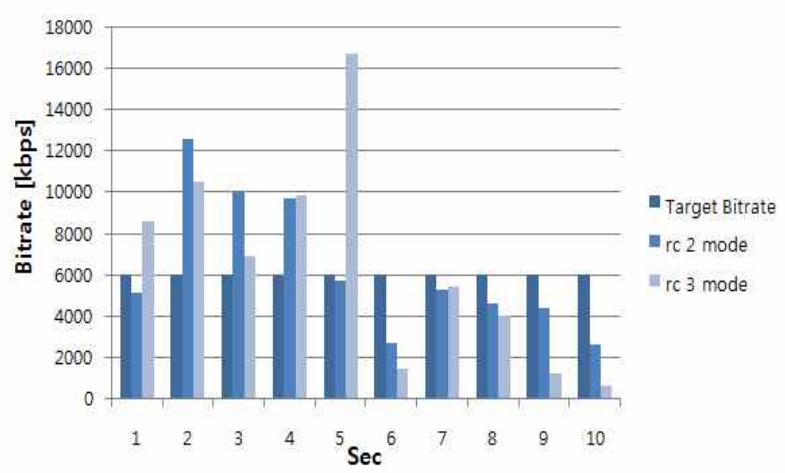

(d) MBC2, $60 \mathrm{fps}$

그림 2. JM을 이용한 초당 발생 비트량

Fig. 2. Bits per sec using JM 
이루어지지 않기 때문이다.

\section{III. 제안하는 비트율 제어 기법}

H.264/AVC에서 사용되고 있는 비트율 제어 알고리즘은 앞서 기술한 바와 같이, 2차 R-D 모델을 이용하여 P-프레 임의 $\mathrm{QP}$ 값을 계산하고, $\mathrm{I}$ 와 $\mathrm{B}$-프레임의 $\mathrm{QP}$ 값들은 $\mathrm{P}-$ 프레 임들의 부호화 결과와 현재 프레임의 계층을 기준으로 결 정함에 따라 I와 B-프레임의 비트율 제어를 정확하게 수행 하지 못한다. 현재 $\mathrm{HEVC}$ 의 공통 실험조건과 같이 $\mathrm{GOP}$ 의 크기를 8 로 설정한 경우에는 $\mathrm{B}$-프레임의 수가 증가함에 따 라 정확한 비트율 제어를 어렵게 한다. 계층적-B 부호화 구 조에서는 각 프레임 타입, 시간계층에 따라 다른 R-D 특성 을 가지기 때문에 각각의 특성을 반영하는 알고리즘의 적 용이 요구된다.

따라서, 본 논문에서는 계층적-B 부호화 구조에서의 모 든 시간계층과 프레임 타입을 고려한 프레임에 대한 목표 비트량을 할당하고, 기존의 2차 R-D 모델을 시간계층과 프
레임 타입에 따라 달리 적용하여 각 프레임의 $\mathrm{QP}$ 를 결정하 는 기법에 대해 기술한다.

제안하는 방식은 크게 1) 목표 비트량 계산, 2) 목표 비트 량에 대한 $\mathrm{QP}$ 값 결정의 2 가지 주요 처리 단계로 구성된 다. 그림 3 과 같이 허용되는 채널 대역폭의 비트율을 입력 하면 GOP, 프레임, 그리고 LCU 단위 순으로 목표 비트량 할당을 한다. 본 논문의 프레임 목표 비트 할당은 계층적-B 부호화 구조를 고려한 SVC(Scalable Video Coding) 비트 율 제어방식 ${ }^{[9]}$ 을 이용한다.

\section{1. 프레임 단위 비트율 제어}

계층적-B 부호화 구조의 프레임 목표 비트할당은 다음 식 (10)에 의해 계산된다.

$$
R_{\Sigma}=(1-\alpha) \times R_{1}+\alpha \times R_{2}
$$

이 때, $\alpha$ 는 [9]에서 고정 상수인 0.75 으로 설정하고, $R_{1}$ 은 식 (11)과 같다.

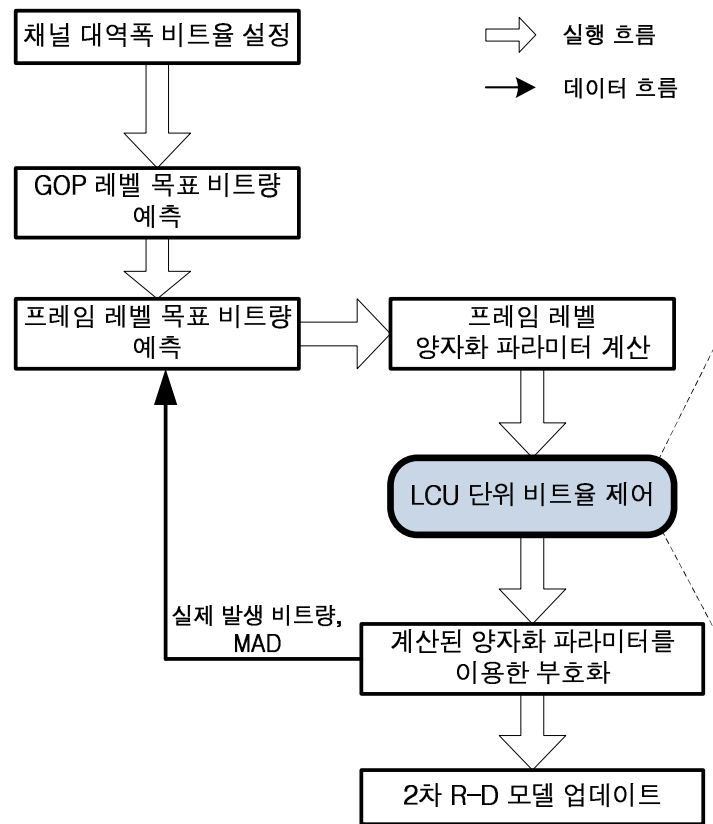

그림 3. 제안하는 비트율 제어의 전체적인 흐름도

Fig. 3. Flow chart of the proposed rate control algorithm

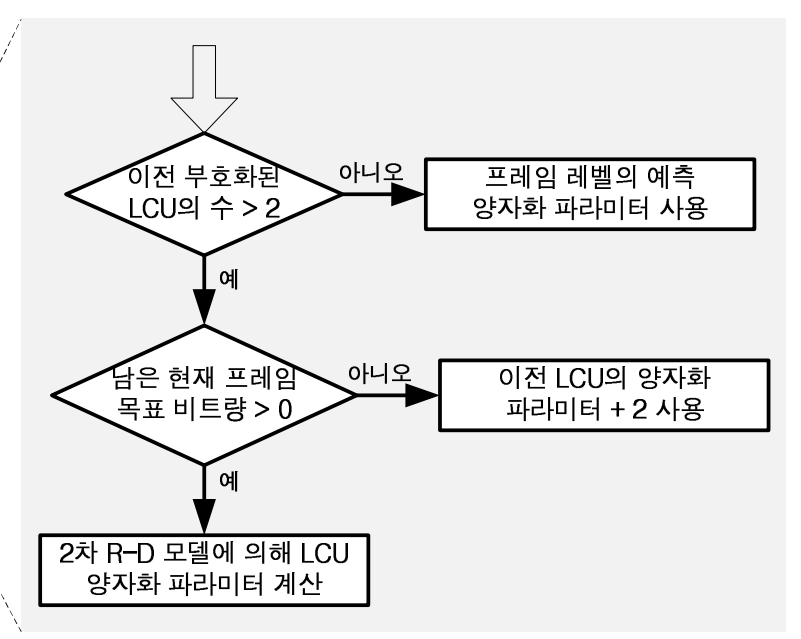




$$
R_{1}=\frac{W}{f}+\beta \times\left(B_{t}-B_{c}\right)
$$

$\beta$ 도 [9]의 상수 0.5 로 설정하고, 이용 가능한 채널 대역폭 $W$, 프레임율 $f$, 목표 버퍼 점유도 $B_{t}$, 그리고 이전의 실제 버퍼 점유도 $B_{c}$ 를 이용하여 $R_{1}$ 을 구한다. 그리고, $R_{2}$ 는 식 (12)와 같다.

$$
R_{2}=R_{r} \times \frac{w_{k}}{w_{\text {sum }}}
$$

현재 프레임이 부호화되기 전의 GOP 내의 잔여 비트량 $R_{r}$, 현재 프레임의 시간계층 $k$ 에서의 가중치 $w_{k}$, 그리고 $\mathrm{GOP}$ 내에 부호화되지 않은 남은 프레임들의 가중치 합 $w_{\text {sum }}$ 을 이용하여 식 (12)를 통해 $R_{2}$ 를 구한다. 가중치 합 $w_{\text {sum }}$ 은 식 (13)과 같이 $\mathrm{GOP}$ 내에 부호화되지 않은 남은 프레임들의 합으로 계산된다.

$$
w_{\text {sum }}=\sum_{k=0}^{L_{\max }} N_{r, k} \times w_{k}
$$

$L_{\max }$ 는 계층적 레벨의 최대값을 의미하고 $N_{r, k}$ 는 $k$ 번째 계층적 레벨에 부호화되지 않고 남아있는 프레임의 수를 말한다. 이 때, 가중치 인자 $w_{k}$ 는 다음 (14)와 같이 실험적 으로 도출할 수 있다.

$$
w_{k}= \begin{cases}6.0 & k=0, \text { Iframe } \\ 4.0 & k=0 \\ 3.5 & k=1 \\ 2.0 & k=2 \\ 1.0 & k=3\end{cases}
$$

이와 같이, 현재 프레임의 목표 비트량을 할당하면 계층 적 부호화 구조에 따른 각 시간계층과 프레임 타입의 특성 을 반영한 비트량을 할당 가능하다.

현재 프레임의 QP를 결정하기 위해서, H.264/AVC의 2 차 R-D 모델을 확장하여 시간계층 $l$, 프레임 타입 $t$ 를 반영 한 식 (15)의 R-D 모델을 제시한다.

$$
\frac{R_{s u m}^{l, t}}{M A D_{c}^{l, t}}=\frac{X_{1}^{l, t}}{Q_{l, t}}+\frac{X_{2}^{l . t}}{Q_{l, t}^{2}}
$$

식 (15)으로부터 식 (10)에서 도출한 프레임 목표할당 비 트량 $R_{s u m}^{l, t}$ 을 이용하여 해당 프레임의 $\mathrm{QP}$ 를 결정한다. 이 때의 $M A D_{c}^{l, t}$ 는 현재 프레임과 같은 시간계층, 프레임 타입 을 가지는 이전의 실제 발생 $M A D$ 값들에 의해 선형 예측된 값이며, 2차 R-D 모델의 파라미터인 $X_{1}^{l, t}, X_{2}^{l, t}$ 는 같은 시간 계층, 프레임 타입에서 발생한 이전의 실제 발생 비트량, 왜곡값, 그리고, 양자화 파라미터에 의해 갱신된 값이다. 이 를 통해, 현재 프레임의 양자화 파라미터 $Q_{l, t}$ 값을 결정하 여 현재 프레임에 적용한다.

\section{LCU 단위 비트율 제어}

$\mathrm{HEVC}$ 에서는 부호화 단위로 $\mathrm{MB}$ 를 확장하여 다양한 블 록 크기를 갖는 $\mathrm{CU}$ 를 정의하고 있으며, 현재 LCU를 $64 \times 64$ 크기로 설정하여 표준화가 진행 중이다. LCU는 기존 $\mathrm{MB}$ 의 16 배의 크기에 해당하는 것으로 프레임과 $\mathrm{MB}$ 사이의 크기이며, 본 논문에서는 부호화기에서의 처리가 용이하도 록 $\mathrm{LCU}$ 를 $\mathrm{BU}$ 로 고려한 비트율 제어 알고리즘을 제시한다.

프레임 내의 번째 LCU의 목표 비트량 $b_{l}$ 은 프레임 레벨 에서 할당된 남은 목표 비트량 $T_{r}$ 을 기반으로 프레임 내의 $\mathrm{LCU}$ 간의 예측된 $\mathrm{MAD}$ 가중치를 이용하여 다음 식 (16)과 같이 할당한다.

$$
\begin{gathered}
b_{l}=T_{r} \times \frac{M A D_{\text {pred,l }}}{M A D_{\text {pred, },}+N_{\text {remain LCU }} \times M A D_{\text {mean }}} \\
M A D_{\text {mean }}=\frac{\sum_{k=1}^{l-1} M A D_{k}}{l-1}
\end{gathered}
$$

현재 부호화하고자 하는 $\mathrm{LCU}$ 의 예측된 왜곡값 $M A D_{\text {pred,l }}$ 과 식 (17)과 같이 이전 $l-1$ 번째까지의 평균 왜 곡값 $M A D_{\text {mean }}$, 그리고 프레임 내에 부호화되지 않고 남은 
$\mathrm{LCU}$ 의 수 $N_{\text {remain } L C U}$ 를 고려하여 전체 복잡도를 도출하고, 그 중에 현재 LCU의 복잡도의 가중치를 고려하여 비트량 을 할당한다.

현재 부호화하는 LCU를 위한 QP 결정 방법은 앞서 기술 한 프레임 단위의 기법과 동일하게 2차 R-D 모델을 이용하 고 위의 식 (16)에서 도출한 LCU의 목표 비트량 $b_{l}$ 을 적용 하여 현재 $\mathrm{LCU}$ 의 $\mathrm{QP}$ 를 결정한다.

이와 같이 현재 LCU에 대한 예측된 $\mathrm{QP}$ 는 위의 그림 3과 같이 다음 3 가지의 경우에 따라 조정된다. 첫 번째, 현재 프레임 내에서 두 번째 이하의 LCU의 경우에는 축적된 데 이터가 없기 때문에 식 (18)과 같이 프레임 레벨에서 예측 한 $\mathrm{QP}$ 를 사용한다.

$$
Q P=Q \hat{P}_{c, f r m}
$$

두 번째, 현재 프레임 내에 부호화되지 않고 남은 LCU에 대해 남은 비트 할당량이 $T_{r} \leq 0$ 일 때, 식 (19)와 같이 이 전 $\mathrm{LCU}$ 의 $\mathrm{QP}$ 값 $Q P_{p, L C U}$ 보다 높은 $\mathrm{QP}$ 값을 할당해 준다.

$$
\begin{gathered}
Q \widehat{P}_{c}=Q P_{p, L C U}+2 \\
Q P=\max \left\{0, Q P_{a p f}-3, \min \left\{51, Q P_{a p f}+3, Q \widehat{P}_{c}\right\}\right\}
\end{gathered}
$$

화질의 급격한 변화를 막기 위해 식 (20)과 같이 이전 프 레임 내 $\mathrm{LCU}$ 의 $\mathrm{QP}$ 평균값 $Q P_{a p f}$ 을 기준으로 한정한다. 세 번째 경우는 그 외의 일반적인 경우로 2 차 R-D 모델에 의 해 계산된 $\mathrm{QP}$ 값을 이용한다.

\section{IV. 실험 및 결과}

본 장에서는 앞에서 제안한 비트율 제어 기법을 $\mathrm{HM}$ 에 구현하여 계층적-B 부호화 구조에 대한 비트율 제어 결과 를 확인한다. 또한, 비트율 제어 알고리즘을 프레임 단위와 $\mathrm{LCU}$ 단위로 설계 및 구현하여 그 결과를 비교한다.

계층적-B 부호화 구조에서의 비트율 제어 실험을 위해 III 장에서 기술한 제안 비트율 제어 알고리즘을 HM 2.0에
구현하였고, $\mathrm{HEVC}$ 표준화의 공통 실험조건에 의한 계층적 -B 부호화 구조인 RA 모드를 사용하였고, 실험조건은 앞의 표 1 과 같다.

표 3은 비트율 제어의 결과로 프레임 단위의 평균 비트율 과 비트율의 정확도를 나타낸 것이고, 표 4는 $\mathrm{LCU}$ 단위의 결과를 보여준다. 본 논문에서는 기존 JM과 달리, 모든 시 간계층에 대해 비트율 제어 모델을 이용하여 $\mathrm{QP}$ 를 결정하 기 때문에 목표 비트율에 근접하는 정확한 평균 비트율을 얻을 수 있음을 확인하였다. 추가적으로, 프레임 단위의 정 확도를 측정하기 위해, 식 (21)에 의해 프레임 단위의 평균 오차율 $m_{E}$ 과 표준 편차 $\sigma_{E}$ 를 사용하였다.

표 3. 프레임 단위 비트율 제어 실험결과

Table 3. Experimental results of frame-level rate control

\begin{tabular}{|c|c|c|c|c|}
\hline $\begin{array}{c}\text { 시퀀스 } \\
\text { (IntraPeriod) }\end{array}$ & $\begin{array}{c}\text { Target } \\
\text { Bitrate } \\
{[\mathrm{kbps}]}\end{array}$ & $\begin{array}{c}\text { Actual } \\
\text { Bitrate } \\
{[\mathrm{kbps}]}\end{array}$ & $\begin{array}{c}\text { Bitrate } \\
\text { Diff. } \\
\left(m_{E} / \sigma_{E}\right)\end{array}$ & $\begin{array}{c}\text { PSNR(Y) } \\
{[\mathrm{dB}]}\end{array}$ \\
\hline \hline Kimono(24) & 920 & 918.65 & $0.32 / 0.29$ & 35.19 \\
\hline ParkScene(24) & 2525 & 2521.48 & $0.47 / 0.58$ & 34.26 \\
\hline BasketballDrive(48) & 2970 & 2972.78 & $0.19 / 0.19$ & 35.00 \\
\hline BQTerrace(64) & 3000 & 2990.86 & $0.89 / 2.42$ & 32.44 \\
\hline KBS2(64) & 5500 & 5501.09 & $0.41 / 1.76$ & 35.46 \\
\hline MBC2(64) & 3000 & 3002.06 & $0.52 / 2.14$ & 40.66 \\
\hline \hline 평균 & & & $0.47 / 1.23$ & 35.50 \\
\hline
\end{tabular}

표 4. LCU 단위 비트율 제어 실험결과

Table 4. Experimental results of LCU-level rate control

\begin{tabular}{|c|c|c|c|c|}
\hline $\begin{array}{c}\text { 시퀀스 } \\
\text { (IntraPeriod) }\end{array}$ & $\begin{array}{c}\text { Target } \\
\text { Bitrate } \\
{[\mathrm{kbps}]}\end{array}$ & $\begin{array}{c}\text { Actual } \\
\text { Bitrate } \\
{[\mathrm{kbps}]}\end{array}$ & $\begin{array}{c}\text { Bitrate } \\
\text { Diff. } \\
\left(m_{E} / \sigma_{E}\right)\end{array}$ & $\begin{array}{c}\text { PSNR(Y) } \\
{[\mathrm{dB}]}\end{array}$ \\
\hline \hline Kimono(24) & 920 & 921.33 & $0.41 / 0.52$ & 35.17 \\
\hline ParkScene(24) & 2525 & 2527.72 & $0.40 / 0.48$ & 34.16 \\
\hline BasketballDrive(48) & 2970 & 2975.11 & $0.21 / 0.29$ & 34.76 \\
\hline BQTerrace(64) & 3000 & 3046.61 & $0.81 / 2.21$ & 32.58 \\
\hline KBS2(64) & 5500 & 5500.65 & $0.23 / 0.31$ & 35.43 \\
\hline MBC2(64) & 3000 & 2999.41 & $0.40 / 0.71$ & 40.56 \\
\hline \hline 평균 & & & $0.41 / 0.75$ & 35.44 \\
\hline
\end{tabular}




$$
E=\sum_{i=1}^{N_{\text {data }}} \frac{\left|T_{i}-S_{i}\right|}{T_{i}}
$$

$T_{i}$ 는 프레임 단위의 목표 비트 할당량, $S_{i}$ 는 비트율 제어 에 의해 발생되는 실제 발생 비트량을 나타낸다. 표 3 과 표 4 를 비교해보면 LCU 단위로 비트율 제어를 수행한 결과의 평균 오차율과 표준 편차가 프레임 단위로 수행한 결과보 다 개선된 것을 확인할 수 있다.

그림 4는 LCU 단위로 비트율 제어를 수행했을 때, 초당 발생되는 비트량 $(\mathrm{kbits} / \mathrm{sec})$ 을 나타낸 것으로 발생되는 초당 부호화 비트량이 목표 비트율에 근접하게 발생함을 확인할 수 있다.

본 논문에서 제안한 방법을 이용한 비트율 제어 기법은 기존 JM의 방법과 다르게, $\mathrm{P}$-프레임뿐만 아니라 I, B-프레

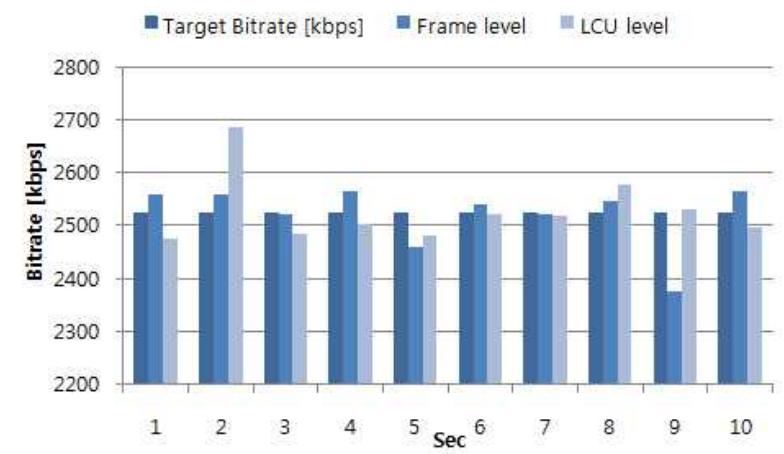

(a) ParkScene, $24 \mathrm{fps}$

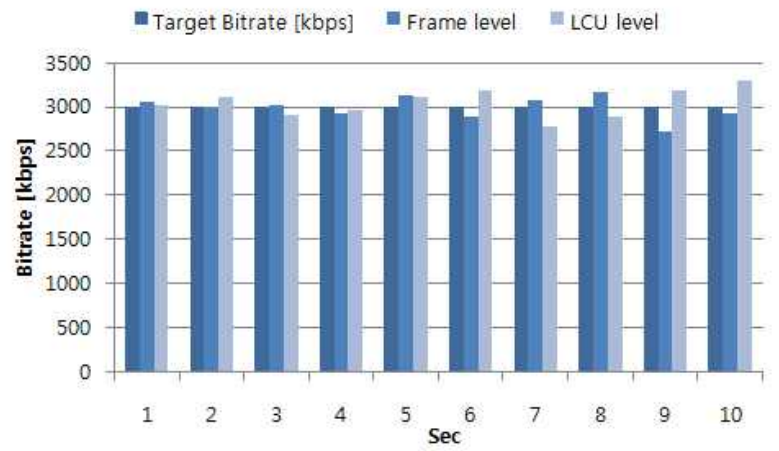

(c) BQTerrace, $60 \mathrm{fps}$
임에 대해서도 비트율 제어 모델을 적용하여 $\mathrm{QP}$ 를 결정한 다. 계층적-B 부호화 구조를 고려하여 각 시간계층과 프레 임 타입에 따라 각기 다르게 발생하는 R-D 특성을 2차 R-D 모델에 반영하여 비트율 제어 정확도를 향상시켰다. 또한, 프레임 단위의 $\mathrm{QP}$ 할당방식에 추가적으로 $\mathrm{LCU}$ 단위까지 목표 비트량을 할당하고 $\mathrm{QP}$ 를 결정함으로써 프레임 단위 의 발생 비트량이 목표 비트량에 대해 평균적으로 $5 \%$ 정도 의 정확도가 향상되었지만 $0.12 \mathrm{~dB}$ 의 PSNR 손실이 있음을 확인하였다. 이는 목표 비트량에 도달하기 위해 LCU단위 로 $\mathrm{QP}$ 를 조절함으로써 나타나는 상충관계를 확인할 수 있 다.

추가적으로, 프레임 단위의 비트율 제어 정확도가 향상 되어 표 5 의 결과와 같은 결과를 확인하였다. 표 5 에 나타 낸 비율은 프레임 목표 비트량이 0으로 설정되는 경우에

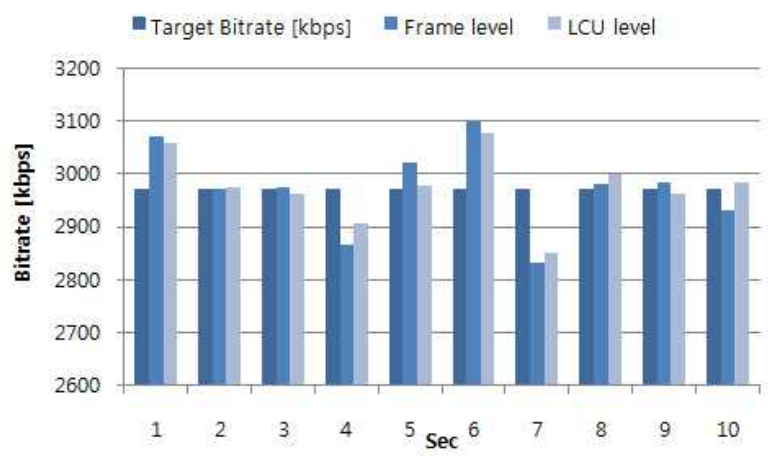

(b) BasketballDrive, $50 \mathrm{fps}$

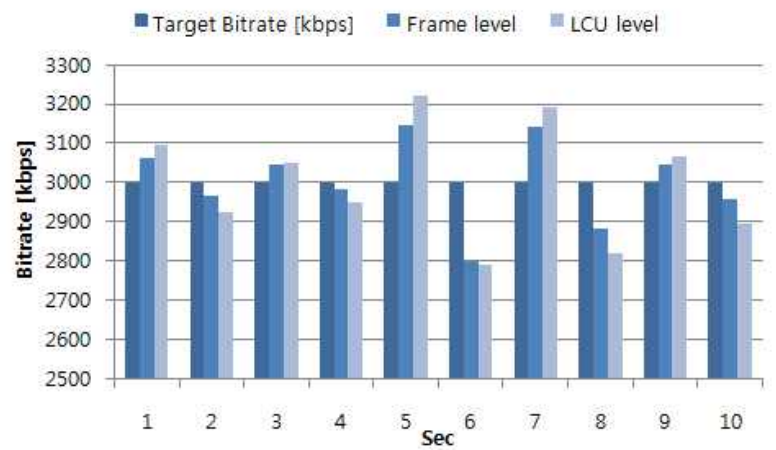

(d) MBC2, $60 \mathrm{fps}$

그림 4. HM을 이용한 초당 발생 비트량

Fig. 4. Bits per sec using $\mathrm{HM}$ 
대한 것으로 이는 GOP에 할당된 비트량을 GOP 내의 프레 임들의 잘못된 QP 예측으로 모두 소진한 경우를 나타낸다. 시퀀스에 따라 차이가 있지만 평균적으로 LCU 단위의 비 트율 제어의 경우, 약 $2 \%$ 정도 향상이 있음을 확인할 수 있다. 즉, 프레임 단위의 비트율 제어의 경우, 한 프레임에 대해 하나의 $\mathrm{QP}$ 값을 할당하므로, 목표로 한 비트량에 근 접하기 어려운 반면, LCU 단위의 비트율 제어의 경우, 현 재 프레임에 할당된 비트량을 LCU 단위로 조절함으로써 향상된 정확도를 얻을 수 있음을 알 수 있다.

표 5. 프레임 목표 비트량이 0 인 비율

Table 5. Percentage of the exhausted frame target bits

\begin{tabular}{|c|c|c|}
\hline 시퀀스 & Frame level[\%] & LCU level[\%] \\
\hline Kimono & 2.08 & 4.58 \\
\hline ParkScene & 4.58 & 1.67 \\
\hline basketballDrive & 0 & 0 \\
\hline BQTerrace & 18.50 & 11.83 \\
\hline KBS2 & 4.33 & 0 \\
\hline MBC2 & 4.17 & 3.83 \\
\hline 평균 & 5.61 & 3.65 \\
\hline
\end{tabular}

\section{V. 결 론}

본 논문에서는 계층적-B 부호화 구조를 갖는 $\mathrm{HEVC}$ 의 $\mathrm{RA}$ 모드에서의 비트율 제어 알고리즘을 구현하고 그 성능 을 분석하였다. 계층적-B 부호화 구조의 시간계층 및 프레 임 타입을 반영하여 기존의 H.264/AVC에 제안된 2차 R-D 모델을 확장한 양자화 파라미터 결정 기법을 제시하였다. 제시된 2차 R-D 모델을 바탕으로 프레임 단위와 LCU 단위 의 비트율 제어 기법을 $\mathrm{HM}$ 에 구현하여 모의실험을 통해 $\mathrm{HEVC} \mathrm{RA} \mathrm{모드에서} \mathrm{비교적} \mathrm{정확한} \mathrm{비트율} \mathrm{제어가} \mathrm{가능함}$ 을 확인하였다.
또한, 프레임과 LCU의 2 가지 기본단위에 대한 비트율 정확도와 화질간의 상충관계를 분석하였다. LCU 단위의 비트율 제어는 프레임 단위의 비트율 제어 대비 평균적으 로 $5 \%$ 정도의 정확도 향상을 보였고 $0.12 \mathrm{~dB}$ 의 PSNR 손실 을 보임을 확인하였다.

이와 같은 비트율 제어의 정확도와 화질열화 간의 상충 관계가 최소가 되는 기본단위의 설정에 대한 추가적인 연 구가 필요하다. 본 논문의 비트율 제어 기법은 추후 표준화 단계에서 계층적-B 부호화 구조를 위한 비트율 제어를 위 한 시험 및 검증에 활용될 수 있을 것으로 기대한다.

\section{참 고 문 헌}

[1] Joint Call for Proposals on Video Compression Technology, ITU-T Q6/16 VCEG 39th meeting, VCEG-AM91, Kyoto, Japan, 17-22 Jan., 2010

[2] T. K. Tan, Gary, J. Sullivan and Jens-Rainer Ohm, The summary of HEVC working draft 1 and HEVC test model (HM), JCTVC-C405, JCT-VC 3rd meeting, Guangzhou, 7-15 Oct., 2010.

[3] HEVC reference software (svn): https:/hevc.hhi.fraunhofer.de/svn/ svn_HEVCSoftware/tags

[4] JCT-VC, Common test conditions and software reference configurations, JCTVC-E700, JCT-VC 5th meeting, Geneva, Mar., 2011.

[5] ISO/IEC 14496-10: Information technology - Coding of audio-visual objects - Part 10: Advanced video coding, 2008.

[6] H.264/AVC reference software: http://iphome.hhi.de/suehring/tml/

[7] Z. Li, W. Gao, F. Pan and K. Pang, Adaptive Basic Unit Layer Rate Control for JVT, Joint Video Team of ISO/IEC MPEG and ITU-T VCEG, JVT-G012, 7th meeting, Pattaya II, Thailand, 7-14 Mar., 2003.

[8] A. Leontaris and A. M. Tourapis, Rate Control reorganization in the Joint Model (JM) reference software, Joint Video Team of ISO/IEC MPEG and ITU-T VCEG, JVT-W042, 23rd meeting, San Jose, California, USA, 21-27 Apr., 2007.

[9] Y. Liu, Z. G. Li and Y. C. Soh, Rate Control of H.264/AVC Scalable Extension, IEEE Trans. Circuits Syst.Video Technol., vol. 17, no. 5, pp. 517-529, May 2007.

[10] 서찬원, 한종기, 계층적 부호화 구조의 H.264/AVC에서 효율적인 비트율 제어를 위한 향상된 비트율-양자화 모델링, 한국방송공학회 추계학술대 회, 2010.

[11] JCT-VC, WD3: Working Draft 3 of High-efficiency video coding, JCTVC-E603, JCT-VC 5th meeting, Geneva, Mar., 2011. 
저 자 소 개

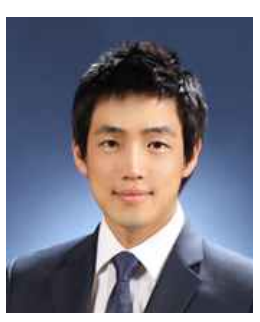

\section{박 동 일}

- 2010년 2월 : 한국항공대학교 항공전자 및 정보통신공학부 학사

- 2010년 3월 현재 : 한국항공대학교 항공전자 및 정보통신공학부 석사과정

- 주관심분야 : 영상부호화, UHDTV, High Efficiency Video Coding

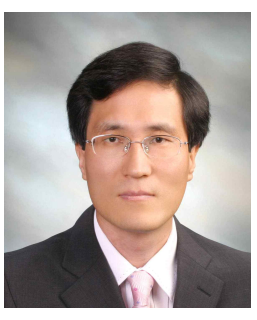

김 재 곤

- 1990년 2월 : 경북대학교 전자공학과 학사

- 1992년 2월 : KAIST전기 및 전자공학과 석사

- 2005년 2월 : KAIST전기 및 전자공학과 박사

- 1992년 3월 2007년 2월 : 한국전자통신연구원(ETRI) 선임연구원/팀장

- 2001년 9월 2002년 11월 : 뉴욕 콜롬비아대학교 연구원

- 2007년 9월 현재 : 한국항공대학교 항공전자 및 정보통신공학부 조교수

- 주관심분야 : 비디오 신호처리/부호화, 디지털방송 미디어, 미디어 컨버전스, 멀티미디어 통신

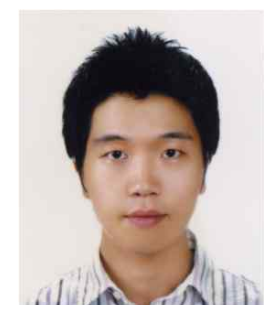

\section{임 성 창}

- 2006년 2월 : 세종대학교 컴퓨터공학과 학사

- 2008년 2월 : 세종대학교 컴퓨터공학과 석사

- 2008년 3월 : 한국전자통신연구원 실감미디어연구팀 연구원

- 주관심분야 : 영상 압축, 영상 처리

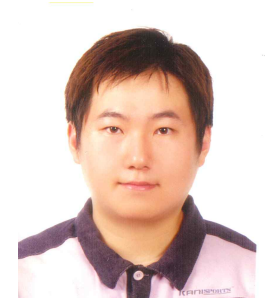

\section{김 종 호}

- 2005년 2월 : 한국해양대학교 제어컴퓨터공학과 학사

- 2007년 8월 : 과학기술연합대학원대학교 (UST) 컴퓨터소프트웨어 및 공학 전공 석사

- 2008년 9월 : 한국전자통신연구원 실감미디어연구팀 연구원

- 주관심분야 : 영상 부호화, 영상 처리

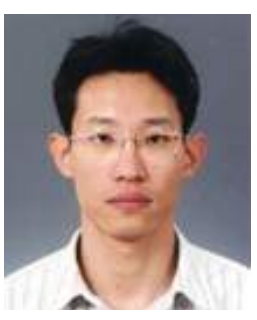

\section{김 휘 용}

- 1994년 8월 : 한국과학기술원 전기및전자공학과 학사

- 1998년 2월 : 한국과학기술원 전기및전자공학과 석사

- 2004년 2월 : 한국과학기술원 전기및전자공학과 박사

- 2003년 8월 2005년 10월 : (주애드팍테크놀러지 멀티미디어 팀장

- 2005년 11월 : 한국전자통신연구원 실감미디어연구팀 선임연구원

- 2006년 9월 2010년 8월 : 과학기술연합대학원대학교(UST) 이동통신및디지털방송공학과 겸임교수

- 주관심분야 : 컴퓨터비전, 영상압축, 멀티미디어시스템 